\title{
A prospective pilot cohort analysis of crash characteristics and pattern of injuries in riders and pillion passengers involved in motorcycle crashes in an urban area in Cameroon: lessons for prevention
}

\author{
Alain Chichom-Mefire ${ }^{1 *}$, Julius Atashili², Jean G. Tsiagadigui ${ }^{3}$, Clovis Fon-Awah² and Marcelin Ngowe-Ngowe ${ }^{2}$
}

\begin{abstract}
Background: Low and middle-income countries carry over ninety per cent of the burden of injury related mortality and disability. Motorcycles are gradually becoming a major mode of transportation in Cameroon and other African countries in the absence of an organized public transport. Consequently, the contribution of motorcycle crash to injury-related deaths seems to be on the rise. Currently, data addressing motorcycle crash characteristics, pattern, and severity of motorcycle-related injuries in Cameroon are scarce. We hypothesised that head and limb injuries are the most frequent cause of morbidity and mortality and equally affect riders and pillion passengers.

Methods: This hospital-based prospective pilot cohort analysis involving 405 motorcycle crashes and 621 injury victims was conducted in Laquintinie Hospital, a large centre located in an urban area in Cameroon. All motorcycle riders and passengers received in the emergency department over a 4 months period with an injury following a traffic related crash were included. Crash characteristics and type, anatomical location and severity of injuries were recorded and analysed comparing the pattern of injuries between riders and pillion passengers involved in motorcyclecrashes. This pilot analysis is expected to propose a snapshot of motorcycle injuries in Douala and will be followed by a larger analysis over a longer period.

Results: We recorded a majority of motorcycle versus car and motorcycle versus motorcycle collisions. Most of these crashes occurred over the week-end and in the night. Helmet use was almost inexistent. We observed that females aged above 40 years represented the majority of pillion passengers. This accounted for the sex-ratio of 1.1/1. A total of 1311 injuries were identified in our patients, giving a mean of 2.1 injuries per victim. The head and the limbs were the most affected anatomical areas. Riders carried a higher risk of sustaining an injury to head and neck than pillion passengers. Riders and pillion passengers carried equal risk of injury to the lower limbs. Emergency room mortality was $4.3 \%$ and riders were more likely to die than pillion passengers.

Conclusion: This study has identified females aged above 40 years as a special vulnerable group in Douala. It also carries strong messages useful for the implementation of preventive measures and management of patients injured in motorcycle-related crash in general.
\end{abstract}

Keywords: Traffic related injuries, Motorcycle, Riders, Pillion passenger, Pattern of lesions, Severity, Outcome

\footnotetext{
* Correspondence: alainchichom@yahoo.com

${ }^{1}$ Faculty of Health Sciences, University of Buea and Regional Hospital Limbe,

P.O. Box 25526, Yaoundé, Cameroon

Full list of author information is available at the end of the article
}

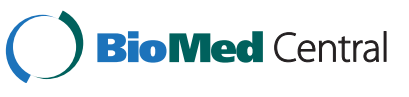

(c) 2015 Chichom-Mefire et al. Open Access This article is distributed under the terms of the Creative Commons Attribution 4.0 International License (http://creativecommons.org/licenses/by/4.0/), which permits unrestricted use, distribution, and reproduction in any medium, provided you give appropriate credit to the original author(s) and the source, provide a link to the Creative Commons license, and indicate if changes were made. The Creative Commons Public Domain Dedication waiver (http://creativecommons.org/publicdomain/zero/1.0/) applies to the data made available in this article, unless otherwise stated. 


\section{Background}

The global burden of injuries is globally on the rise [1-3]. Injuries will likely become the fourth leading cause of mortality and disability worldwide by 2030 [4]. Low and middle income countries (LMICs) are disproportionately affected, accounting for over $90 \%$ of the overall injury related mortality [3]. Most of these deaths are attributable to motor vehicle crash. According to World Health Organization (WHO), in 2002 traffic related injuries killed an estimated 1.2 million people and injured more than 50 million others [5]. In African countries, it has been estimated that the number of people who die in traffic related injuries will undergo a $144 \%$ increase between 1990 and 2020 [6].

Current data on injuries have permitted the identification of vulnerable road users. It appears that pedestrians and motorised two-wheeled vehicle users get injured on the road more frequently and more severely than other road users [7-15]. Analysis of motor vehicle crash related deaths indicates that over $40 \%$ of victims are motorised two-wheeled vehicle users [10, 14].

Despite these established facts, motorcycle use as a mean of transportation is on the rise worldwide $[7,15,16]$. In Sub-Saharan African countries, the motorcycle and motorized two-wheelers have emerged as a popular commercial mode of transportation without any corresponding improvement and adaptation of road infrastructures $[8,17,18]$. This is particularly true for Cameroon where road infrastructures are generally considered very poor. It has been estimated that the number of people who die as a result of traffic injuries in this country is 35 times higher than what has been reported on similar road infrastructures in the United States of America and usually concerns vulnerable road users [19]. One third of traffic injury victims in large cities of Cameroon are motorcyclists [20]. Commercial motorcyclists popularly known in Douala as "Bend Skin" are a very frequently used a mode of transportation in the absence of any regular organized public transport. "Bend Skins" have become a prominent feature displayed on the roads in Douala. The motorcycle operators (riders) generally lack training, operate without a driving licence and the rules about helmet use and drunk driving which exist in Cameroon are generally not implemented.

The profile of motorcycle crash victims and other factors determining nature and severity of injuries have been studied, especially in developed countries [13, 15, 21, 22]. Many recent reports indicate that motorcycle accident victims are young males $[11,16,21,23]$ who display a unique pattern of injuries with a greater vulnerability of head and lower limbs [11, 16, 21, 24]. Few reports have shown interest in the differential analysis of injuries and their severity between riders and passengers [16, 21, 24].
While in developed countries, effective intervention plans are implemented with measurable results [25-27], low and middle income countries still lack the most basic epidemiological data.

In Cameroon, no study has specifically addressed the problem of motorcycle related injuries. Without such data, no reasonable and efficient policy of control of these injuries can be implemented.

The aim of this study was to describe the crash characteristics and epidemiological profile of motorcyclerelated injury victims in a large hospital in Douala, Cameroon. We also analysed the pattern of injuries and in-hospital outcome comparing riders and pillion passengers. We hypothesized that most victims of motorcycle related crash are injured in a car versus motorcycle collision, that males below 40 years represent the large majority of cases and that the head and lower limb are the most affected body areas for both riders and passengers.

\section{Methods}

\section{Study design and settings}

This prospective cohort study was conducted in the emergency department of Laquintinie Hospital located in Douala, Cameroon over a four months period, from January $1^{\text {st }}$ to April $30^{\text {th }} 2012$. Douala is the largest city of Cameroon with a total population estimated to be over 2.3 million inhabitants in 2010.

Laquintinie hospital is the largest referral centre in the country with a total capacity of over 450 beds. It possesses most specialized services, including an emergency department which is functional round the clock. The hospital is opened to the public but access to health care is selective based on financial resources in the absence of insurance plans and a social management system. Victims of motorcycle crash are admitted in a special 30 beds "bend skin" unit.

\section{Ethical considerations and patient consent}

This study was approved by the institutional review board of the Faculty of Health Sciences of the University of Buea under number 2012-07-0054. Written consent to participate to the study was obtained either from the patient or a family member whenever possible. When this procedure could not be followed, a provisional administrative consent was requested from the hospital administration and patients who later on refused to participate were excluded from the cohort.

\section{Study participants and data collection}

During the study period, all cases received in the emergency department of Laquintinie hospital after a trafficrelated injury involving a motorcycle were identified. We included in the study all drivers (referred to in this study 
as riders) and pillion passengers of a motorcycle admitted in the emergency department for an injury sustained while they were involved in a motorcycle crash. All other cases of injury were excluded. Patients for whom basic epidemiological data such as age and sex could not be obtained, those who arrived dead, and those who did not consent were also excluded. Patients for whom inward admission was decided after initial management in the emergency department were followed-up in the corresponding ward for a maximum period of 7 days.

The data recorded included the following:

a) Patient's characteristics: epidemiological variables and profession.

b) Crash characteristics: day and time of crash, type of collision, number of passengers on the motorcycle at the time of crash, position of the patient (rider or passenger), rider's experience, helmet use and the notion of alcohol consumption within $6 \mathrm{~h}$ prior to the crash. For the purpose of description, we divided the days of a week to define week-days (from Monday to Thursday) and week-ends (from Friday to Sunday). We also divided the $24 \mathrm{~h}$ of a day as day time (from 6:00 am to 5:59 pm) and night (from 6:00 pm to 5:59 am). A commercial motorcyclist was defined as any person driving a motorcycle and transporting passengers against a payment.

c) Lesions identified and recorded: Description of these lesion included identification of anatomical location, detailed description of the lesion, estimation of Glasgow Coma Scale and estimation of overall severity of injury using the Injury Severity Score (ISS).

d) Outcome in the emergency department: discharge, inward admission, referral to another institution, or death in the emergency department or within 7 days following admission.

\section{Statistical analysis}

Data were analysed using Epi-info ${ }^{\circ}$ 2003. Student's t test, chi-square or Fisher's exact test were used to compare means and proportions. Results were considered significant for $p$-values less than 0.05 .

\section{Reporting}

The "Strengthening the Reporting of Observational Studies in Epidemiology" (STROBE) guidelines were used in reviewing and reporting the study [28].

\section{Results}

\section{Patient's characteristics}

A total of 645 motorcycle crash victims were admitted in the emergency department. Twenty four (3.7 \%) patients were excluded: four patients were declared dead on arrival, six did not have information on age and/sex available and fourteen declined to participate in the study. A total of 621 cases could finally be analyzed. These patients were involved in 405 motorcycle crashes.

The ages ranged from 4 to 85 years with a mean of $34.9 \pm 16.8$ years.

They were 325 males and 296 females, giving a sexratio of $1 \cdot 1 / 1$.

As Fig. 1 show, the majority of patients $(57.6 \%)$ were aged $21-40$ years. Patients aged between 41 and 60 years represented $25 \%$ of the study population. Male sex significantly predominated in patients aged $21-40$ years, while the female sex predominated in patients aged $41-60$ years $(p<0.0001)$.

A total of $246(39.6 \%)$ patients were riders, all males. These included the 191 (77.6 \%) commercial motorcyclists. The number of females who were pillion passengers $(79 \%)$ was significantly higher $(P<0.0001)$.

Figure 2 shows the different professional categories involved in motorcycle crashes in Douala. Commercial

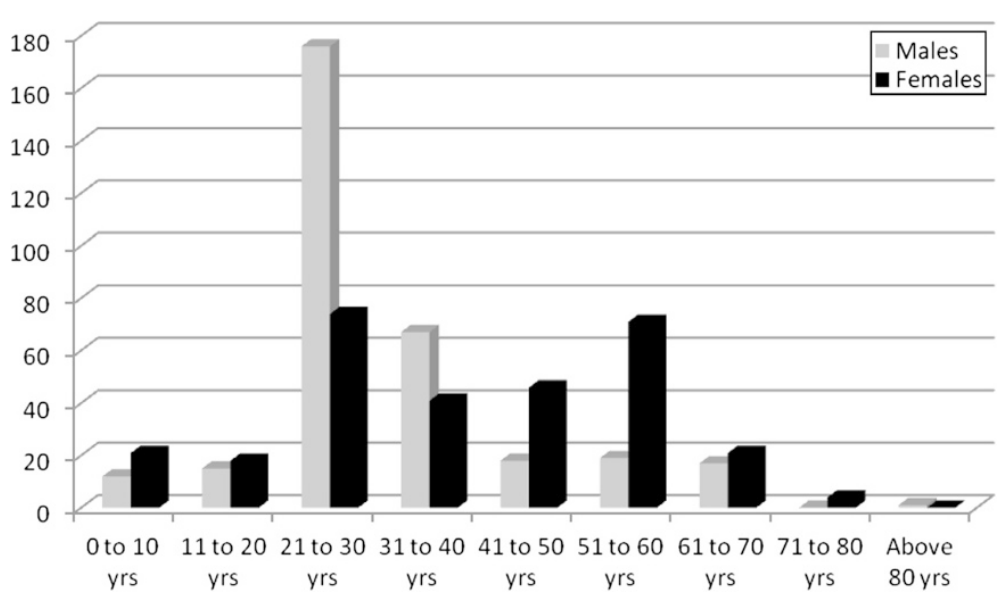

Fig. 1 Distribution of motorcycle crash victims according to age and sex 


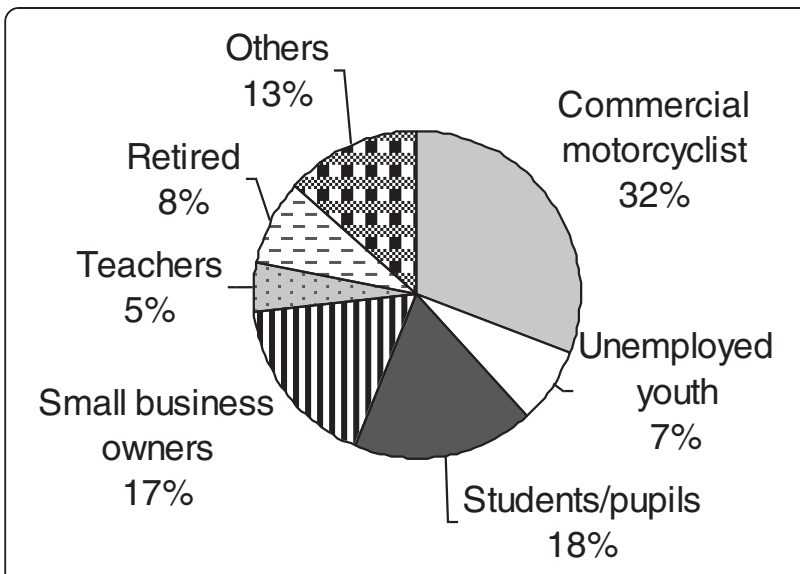

Fig. 2 Distribution of motorcycle crash victims according to professional groups

motorcycle riders were the most affected professional group $(n=191)$.

\section{Crash characteristics}

As Fig. 3 shows, a significant higher number (63.7\%) of crashes occurred over night $(p<0.0001)$. The risk of motorcycle crash was significantly higher on week-ends than on week-days $(p<0.0001)$.

Twenty two (9\%) of riders admitted alcohol consumption within $6 \mathrm{~h}$ prior to the crash. Half of the riders had more than 5 years experience.

Concerning helmet use, only 14 riders (5.7 \%) and no passenger $(0 \%)$ had a helmet on at the time of the accident.

As Fig. 4 shows, each motorcycle carried a mean 2.36 persons at the time of accident. A total of 147 (36.2\%) motorcycles carried 3 persons or more.

Figure 5 indicates that collision between motorcycle and motor-vehicle $(n=162)$ or with another motorcycle $(n=77)$ represented $60 \%$ of all crashes.

\section{Pattern of injuries}

A total of 1311 injuries were identified in our 621 victims giving a mean of 2.1 injuries per victim. As many as $429(69 \%)$ had more than one injury recorded. Limbs $(n=551)$, head and neck $(n=318)$, and abdomen $(n=$ 194) were the most frequently injured anatomical regions (Fig. 6). Riders carried a higher risk of sustaining an injury to head and neck than pillion passengers $(p<$ $0.0001)$. Riders and pillion passengers carried equal risk of injury to the lower limbs $(p=0.15)$.

As Table 1 shows, globally, soft tissue lesions represented almost $65 \%$ of lesions recorded.

The Glasgow coma scale (GCS) could be estimated in 588 patients. It ranged from 3 to 15 with a mean of $14 \cdot 1$. A total of $538(91.5 \%)$ patients had a GCS of 13 or more.

According to Table 2, more than $53 \%$ of fractures were located in the lower limb and $21 \%$ in the upper limb. The most commonly fractured site was the leg with $113(37.8 \%)$ of cases involving the tibia/fibula.

ISS could be calculated precisely in 534 (86 \%) patients. It ranged from 1 to 41 with a mean of $7.4 \pm 9.6$. It was 8.8 for riders and 5.9 for passengers. Mean ISS was significantly higher for riders than for pillion passengers $(p<0.001)$.

\section{Outcome}

Analysis of the destination of patients after receiving treatment in the emergency department indicated that $418(67.3 \%)$ of patients were discharged back home, 126 (20.3\%) were admitted in one of the surgical wards or in the operation room and $38(6.1 \%)$ patients were admitted in the Intensive Care Unit. This gave an overall admission rate of $26.4 \%$. Referral to another centre concerned $12(2 \%)$ of patients. Twenty seven patients (4.3\%) died. Thirteen died in the emergency department and fourteen others died within seven days following admission. Mortality rate was significantly higher for riders

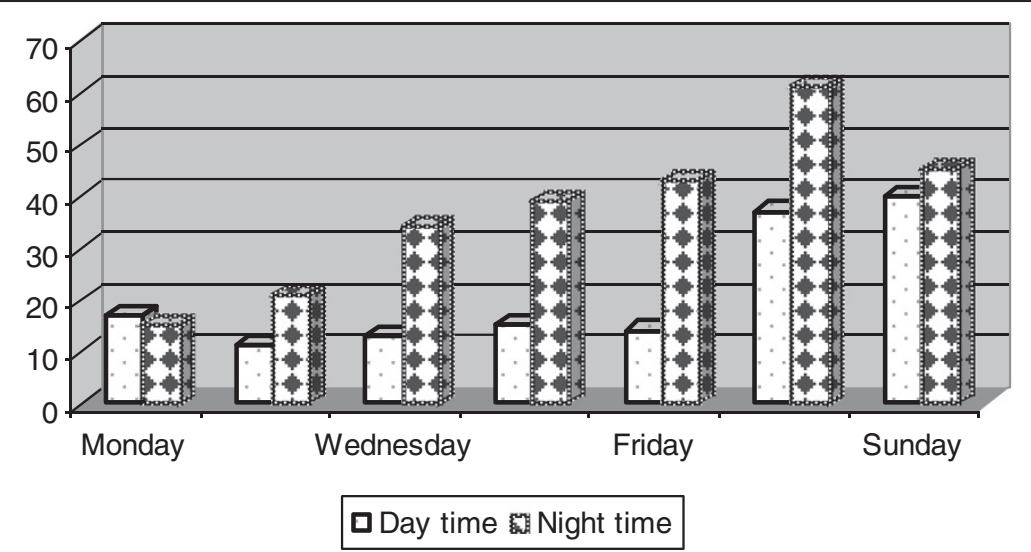

Fig. 3 distribution of motorcycle crashes in Douala according to day and time 


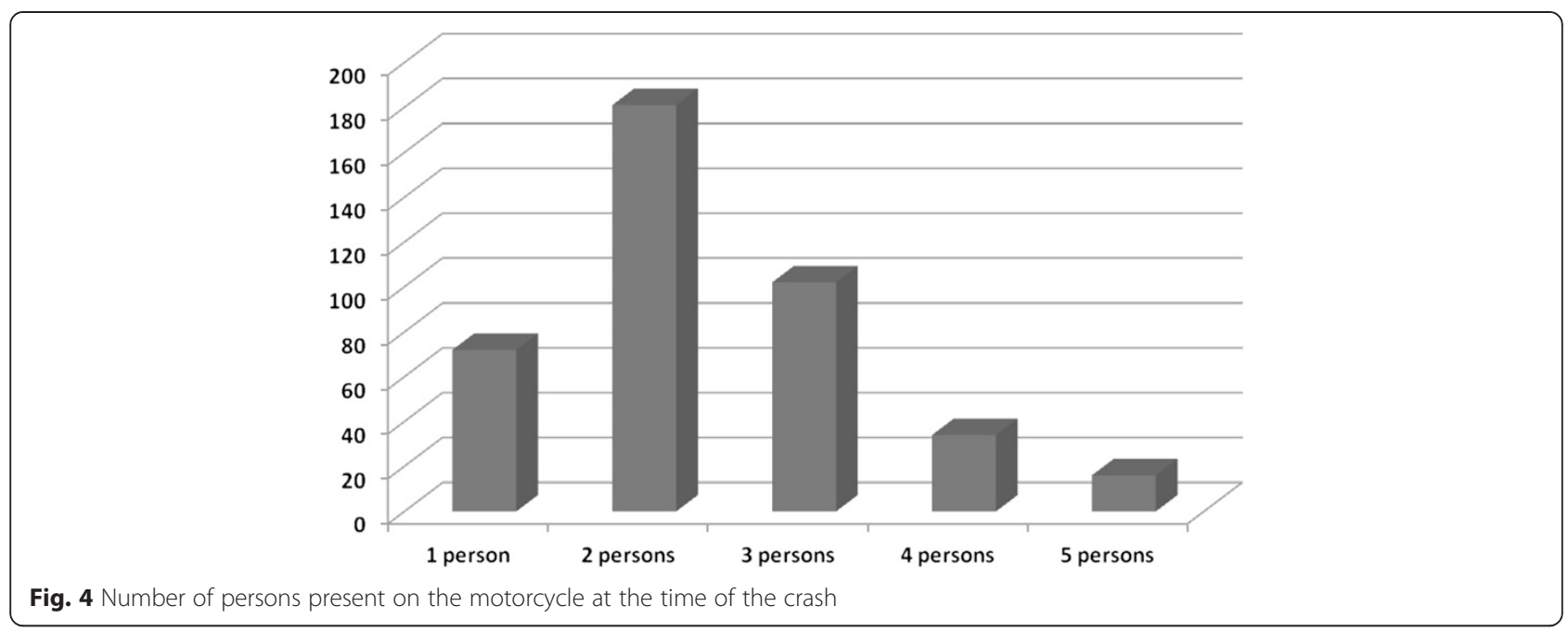

(6.9 \% fatality rate) than for passengers (2.7\% fatality rate), $(P=0.011)$. Mean GCS was significantly lower in those who died than in those who survived $(p<0.0001)$. Mean ISS (16.3) was significantly higher in those who died than in those who survived $(p<0.0001)$.

\section{Discussion}

To the best of our knowledge, this is the first report of a cohort analysis exclusively devoted to the problem of motorcycle related injuries in an urban centre in SubSaharan Africa with regards to crash and patient's characteristics and pattern of injuries.

Our findings indicate that motorcycle related injury victims consulting in Laquintinie Hospital can be divided into two main age groups with different sexdistribution: the classical group of patients aged 20 to 40 years with a majority of males and a second group of patients aged 41 to 60 years with a majority of females who are most often pillion passengers. As many as one third of crash victims develop a serious injury including head injuries and fractures. They generally get injured while circulating without a helmet over the week-end and in the night. The crash usually results from collisions with a motor-vehicle or another motorcycle. Motorcycles involved in crashes in Douala are often

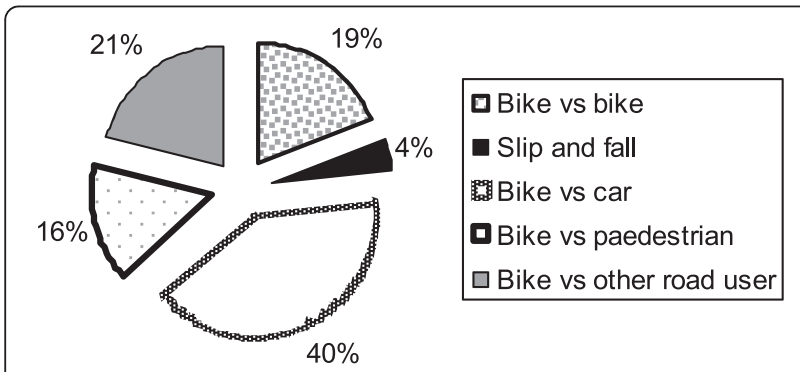

Fig. 5 Distribution of our motorcycle crashes according to type of collision overloaded. Head and limb appear to be the most affected anatomical body areas. Death affects riders more than pillion passengers and usually occurs as a consequence of head involvement.

The main limitation of this study is the fact that it is not a community based study.

Some other concerns are likely to interfere with the generalizability of our results. The analysis of head involvement using GCS and the estimation of the overall severity of injury using ISS could be biased by the fact that these data were not available for all patients. However, these problems concerned a limited number of patients, generally less than $10 \%$.

The group of patients aged between 20 and 40 years is the typical age group of injury victims in general and motorcycle crash victims in particular as reported in most available studies $[7,19,23,25,26,29,30]$. But the second peak of incidence described in our report which concerns patients aged 41-60 years with a large majority of females, mostly pillion passengers is unusual. This feature probably accounts for the unprecedented sexratio of 1.1/1 described in our report. All existing studies report a male to female ratio ranging from $2.5 / 1$ to $46.5 /$ $1[11,16,17,21-23,25,30,31]$. Many describe a massive male predominance above $95 \%[11,22,31]$. Fitzharris et al. also reported a very large majority of male riders, but only $30 \%$ of their passengers were females [21].

These findings could be an indication of a greater involvement of females in income generating activities in Douala. This could also reflect a reduction in the perception of the risk of motorcycle crash in females aged above 40 years. Generally, African countries completely lack studies addressing the issue of perception of the risk of traffic related injuries of all types [32].

The analysis of crash characteristics confirms the vulnerability of motorcycles to other motorised road users 


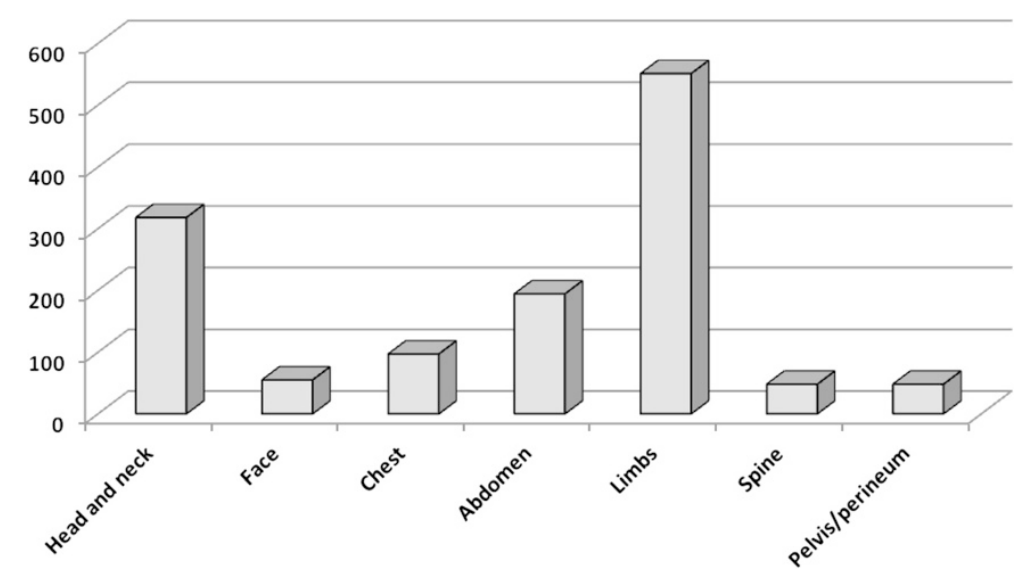

Fig. 6 Distribution of motorcycle crash victims in Douala according to the anatomical region injured

$[11,16,30,33]$, especially in the night $[21,23]$ when activities are shifted in the most popular areas of the city. In a recent report from a country with similar characteristics, nearly $50 \%$ of commercial motorcyclists admitted carrying two to four pillion passengers [34]. The high rate of collision between two motorcycles described in our report is rare in the literature. Also, our study identified neither injuries sustained in a collision between a motorcycle and a road obstacle such as a tree nor the classical "slide and fall" mechanism. This is probably explained by the fact that in Douala roads are designed for car use with no motorcycle bands and no obstacles. Cars and motorcycles then share the same driving space and this favours the car versus motorcycle collision.

Table 1 Nature of lesion in victims of motorcycle crashes in Douala, Cameroon

\begin{tabular}{lll}
\hline Lesion & Number & Percentage \\
\hline $\begin{array}{l}\text { Abrasions/Bruises (defined as lesions not } \\
\text { requiring suturing) }\end{array}$ & 498 & 38 \\
$\begin{array}{l}\text { Lacerations (defined as lesions requiring } \\
\text { suturing) }\end{array}$ & 352 & 26.8 \\
$\begin{array}{l}\text { Traumatic brain injury } \\
\text { Bone fractures }\end{array}$ & 46 & 3.5 \\
Joint dislocations & 299 & 22.9 \\
Limb traumatic amputations & 7 & 0.5 \\
Haemothorax/Pneumothorax & 13 & 1 \\
Blunt injury to the abdomen & 8 & 0.6 \\
Penetrating abdominal injury & 36 & 2.7 \\
Urethral rupture & 4 & 0.3 \\
Injury to the anus & 1 & 0.1 \\
Spinal cord injury & 1 & 0.1 \\
Crush injury to a limb & 10 & 0.8 \\
Total & 36 & 2.7 \\
\hline
\end{tabular}

Many previous reports describe the pattern of injuries specific to motorcycle crash victims and the vulnerability of head and lower limbs [11, 12, 15, 17, 22, 23, 31, 35], often in combination [25]. Generally, head involvement is responsible for or is a major contributor to death $[12,17,22,23,33]$. Limbs generally seem to be vulnerable to fractures, particularly the tibia and fibula $[11,25,31,36]$. However, very few reports compare riders and pillion passengers in terms of anatomical location and severity of injuries [21, 24, 26]. Contrary to our description of a greater vulnerability of the head in riders, Fitzharris et al. reported no or few differences between riders and passengers in terms of anatomical location and severity of injury [21]. Zhao et al. rather report a greater vulnerability of hands, perineum, chest, and abdomen in riders [24]. This is probably related to a greater rate of helmet users in the areas where these other studies were conducted.

The low mean ISS score probably accounts for the low Intensive Care Unit admission rate and low mortality rate generally reported $[13,23,31]$.

This hospital-based analysis can serve as a baseline for understanding the specific problem of motorcycle related injuries in the city of Douala. It is also an invitation for a more in-depth analysis which would ideally be community based or at least include most health institutions in Douala which are involved in the management of injury victims. This would help confirm some of our findings such as the identification of a new vulnerable group represented by females aged above 40 years. There is need to design a special message for these females who use commercial motorcycles as a mean of transportation to increase their awareness of the dangers of motorcycle use in the absence of protective measures.

The other findings, especially those related to crash characteristics are likely to reflect the general features of traffic crash involving motorcycles in other urban 
Table 2 Distribution by fracture site of victims who sustained a fracture in a study of motorcycle crash victims in Douala, Cameroon

\begin{tabular}{lll}
\hline Site & Number & Percentage \\
\hline Skull & 24 & 8 \\
Spine & 16 (6 cervical spine) & $5 \cdot 3$ \\
Maxillo-facial & 17 & $5 \cdot 7$ \\
Ribs & 19 & $6 \cdot 4$ \\
Upper limb & & \\
Clavicle/scapula & 2 & $0 \cdot 7$ \\
Humerus & 20 & $6 \cdot 6$ \\
Radius/Ulna & 29 & $9 \cdot 7$ \\
Wrist and hand & 12 & 4 \\
Lower limb & & \\
Pelvis girdle & 11 & $3 \cdot 7$ \\
Femur & 19 & 6.4 \\
Tibia/fibula & 113 & $37 \cdot 8$ \\
Foot & 17 & $5 \cdot 7$ \\
Total & 299 & 100 \\
\hline
\end{tabular}

areas of Cameroon where the absence or the nonimplementation of legal measures is the rule. They clearly indicate the need for action on a number of well known modifiable cost-effective risk factors of motorcycle related injuries such as helmet use and reflective coats in the night for both riders and passengers and the limitation of the number of pillion passengers. Long term measures such as redesigning the roads and rules of circulation to avoid mixing of incompatible users should also be considered.

\section{Conclusions}

In the context of the high and increasing use of motorcycles for commercial purposes in Douala and urban settings in sub-Saharan Africa, the data provided by this study on the nature and severity of these injuries are likely to contribute to the conception and implementation of preventive measures as well as the planning of appropriate specific care to be provided to this category of injury patients. These findings confirm the growing problem of motorcycle injuries in LMICs and a strong recommendation towards the need of developing organized urban transports in Douala and other large cities in Cameroon. The findings of this report would also contribute in the design of national and international guidelines targeting motorcycle injuries and taking into account some of the crash characteristics highlighted in this study such as night collisions and the large number of females passengers. A more comprehensive approach starting from the site of accident and targeting head and limb involvement is more likely to reduce the burden of these injuries in terms of mortality and disability.

\section{Competing interests}

The authors declare that they have no competing interests.

\section{Author's contribution}

A C-M designed the study, contributed in protocol writing, data collection, statistical analysis, writing and revising the manuscript. JA contributed in designing the study, analysed the data and revised the final version of the manuscript. JGT contributed in data collection and revised the manuscript. C F-A Contributed in study design, protocol writing, data collection, statistical analysis and drafting the manuscript. M N-N contributed in data analysis and revision of the final version of the manuscript. All authors read and approved the final manuscript.

\section{Authors' information}

Not applicable.

Availability of data and materials

Not applicable.

Funding

Source of funding: none.

\section{Author details}

${ }^{1}$ Faculty of Health Sciences, University of Buea and Regional Hospital Limbe, P.O. Box 25526, Yaoundé, Cameroon. 'Faculty of Health Sciences, University of Buea, Buea, Cameroon. ${ }^{3}$ Surgical Unit, Laquitinie Hospital, Douala, Cameroon.

Received: 31 December 2014 Accepted: 15 September 2015 Published online: 18 September 2015

\section{References}

1. Mathers CD, Boerma T, Ma FD. Global and regional causes of death. Br Med Bull. 2009;92:7-32.

2. Murray CJ, Lopez AD. Mortality by cause for eight regions of the world: Global Burden of Disease Study. Lancet. 1997;349(9061):1269-76.

3. Nordberg E. Injuries as a public health problem in sub-Saharan Africa: epidemiology and prospects for control. East Afr Med J. 2000;77(12 Suppl):S1-43.

4. Mathers CD, Loncar D. Projections of global mortality and burden of disease from 2002 to 2030. PLoS Med. 2006;3(11), e442.

5. Peden $M$, Scurfi Eld $R$, Sleet $D$, et al. World report on road traffic injury prevention. Geneva: World Health Organization; 2004.

6. Kopits E, Cropper M. Traffic fatalities and economic growth. Accid Anal Prev. 2005;37:169-78.

7. Keall MD, Newstead S. Analysis of factors that increase motorcycle rider risk compared to car driver risk. Accid Anal Prev. 2012;49:23-9.

8. Chichom Mefire A, Etoundi Mballa GA, Azabji Kenfack M, Juillard C, Stevens K. Hospital-based injury data from level III institution in Cameroon: Retrospective analysis of the present registration system. Injury. 2013;44(1):139-43.

9. Odero W, Garner P, Zwi A. Road traffic injuries in developing countries: A comprehensive review of epidemiological studies. Trop Med Int Health. 1997;2:445-60

10. Santamariña-Rubio E, Pérez K, Ricart I, Arroyo A, Castellà J, Borrell C. Injury profiles of road traffic deaths. Accid Anal Prev. 2007;39(1):1-5.

11. Lateef F. Riding motorcycles: is it a lower limb hazard? Singapore Med J. 2002;43(11):566-9.

12. Lin MR, Kraus JF. A review of risk factors and patterns of motorcycle injuries. Accid Anal Prev. 2009;41(4):710-22.

13. Cunningham G, Chenik D, Zellweger R. Factors influencing motorcycle crash victim outcomes: a prospective study. ANZ J Surg. 2012;82(7-8):551-4.

14. Beck LF, Dellinger AM, O'Neil ME. Motor vehicle crash injury rates by mode of travel, United States: using exposure-based methods to quantify differences. Am J Epidemiol. 2007;166(2):212-8.

15. Markogiannakis H, Sanidas E, Messaris E, Koutentakis D, Alpantaki K, Kafetzakis A, et al. Motor vehicle trauma: analysis of injury profiles by roaduser category. Emerg Med J. 2006;23(1):27-31.

16. Zargar M, Khaji A, Karbakhsh M. Pattern of motorcycle-related injuries in Tehran, 1999 to 2000: a study in 6 hospitals. East Mediterr Health J. 2006;12(1-2):81-7. 
17. Nwadiaro HC, Ekwe KK, Akpayak IC, Shitta H. Motorcycle injuries in northcentral Nigeria. Niger J Clin Pract. 2011;14(2):186-9.

18. Juillard C, Etoundi Mballa GA, Bilounga Ndongo C, Stevens KA, Hyder AA. Patterns of Injury and Violence in Yaoundé Cameroon: An Analysis of Hospital Data. World J Surg. 2010;29.

19. Sobngwi-Tambekou J1, Bhatti J, Kounga G, Salmi LR, Lagarde E. Road traffic crashes on the Yaoundé-Douala road section, Cameroon. Accid Anal Prev. 2010;42(2):422-6. doi:10.1016/j.aap.2009.09.003.

20. McGreevy J1, Stevens KA2, Ekeke Monono M3, Etoundi Mballa GA4, Kouo Ngamby M5, Hyder AA6, et al. Road traffic injuries in Yaoundé, Cameroon: A hospital-based pilot surveillance study. Injury. 2014;45(11):1687-92.

21. Fitzharris M, Dandona R, Kumar GA, Dandona L. Crash characteristics and patterns of injury among hospitalized motorised two-wheeled vehicle users in urban India. BMC Public Health. 2009;9:11.

22. Crandon IW, Harding HE, Cawich SO, McDonald AH, Fearron-Boothe D. Motorcycle accident injury profiles in Jamaica: an audit from the University Hospital of the West Indies. Int J Inj Contr Saf Promot. 2009;16(3):175-8.

23. Sirathranont J, Kasantikul V. Mortality and injury from motorcycle collisions in Phetchaburi Province. J Med Assoc Thai. 2003;86(2):97-102.

24. Zhao H, Chen R, Deng G, Yin Z, Yang G, Liu S, et al. Comparison of injuries sustained by drivers and pillion passengers in fatal head-on motorcycle collision accidents. Forensic Sci Int. 2011;207(1-3):188-92.

25. Alıcıoğlu B, Yalnız E, Eşkin D, Yılmaz B. Injuries associated with motorcycle accidents. Acta Orthop Traumatol Turc. 2008;42(2):106-11.

26. Bradbury A, Robertson C. Pattern and severity of injury sustained by motorcyclists in road traffic accidents in Edinburgh, Scotland. Health Bull (Edinb). 1993;51 (2):86-91.

27. Ameratunga S, Hijar M, Norton R. Road-traffic injuries: Confronting disparities to address a global-health problem. Lancet. 2006;367:1533-40.

28. Von Elm E, Altman DG, Egger M, et al. The Strengthening the Reporting of Observational Studies in Epidemiology (STROBE) statement: guidelines for reporting observational studies. Lancet. 2007;370(9596):1453-7.

29. Oginni FO, Ugboko VI, Adewole RA. Knowledge, attitude, and practice of Nigerian commercial motorcyclists in the use of crash helmet and other safety measures. Traffic Inj Prev. 2007;8(2):137-41.

30. Nzegwu MA, Aligbe JU, Banjo AA, Akhiwui W, Nzegwu CO. Patterns of morbidity and mortality amongst motorcycle riders and their passengers in Benin-City Nigeria: one-year review. Ann Afr Med. 2008;7(2):82-5.

31. Hefny AF, Barss P, Eid HO, Abu-Zidan FM. Motorcycle-related injuries in the United Arab Emirates. Accid Anal Prev. 2012;49:245-8.

32. Lagarde E. Road traffic injury is an escalating burden in Africa and deserves proportionate research efforts. PLoS Med. 2007:4(6), e170.

33. Solagberu BA, Ofoegbu CK, Nasir AA, Ogundipe OK, Adekanye AO, Abdur-Rahman LO. Motorcycle injuries in a developing country and the vulnerability of riders, passengers, and pedestrians. Inj Prev. 2006;12(4):266-8.

34. Oginni FO, Ugboko VI, Ogundipe O, Adegbehingbe BO. Motorcycle-related maxillofacial injuries among Nigerian intracity road users. J Oral Maxillofac Surg. 2006;64(1):56-62.

35. Parreira JG, Gregorut F, Perlingeiro JA, Solda SC, Assef JC. Comparative analysis of injuries observed in motorcycle riders involved in traffic accidents and victims of other blunt trauma mechanisms. Rev Assoc Med Bras. 2012;58(1):76-81.

36. Peek C, Braver ER, Shen H, Kraus JF. Lower extremity injuries from motorcycle crashes: a common cause of preventable injury. J Trauma. 1994;37(3):358-64.

\section{Submit your next manuscript to BioMed Central and take full advantage of:}

- Convenient online submission

- Thorough peer review

- No space constraints or color figure charges

- Immediate publication on acceptance

- Inclusion in PubMed, CAS, Scopus and Google Scholar

- Research which is freely available for redistribution 